\title{
OS TEMAS, FIGURAS E ISOTOPIAS EM ÍTALO CALVINO
}

\author{
Maria Magda de Lima Santiago (Faculdade de Letras/UFMG ${ }^{1}$ )
}

\section{Introdução}

O texto escolhido para análise inicia a segunda parte do livro As Cidades Invisiveis, de Ítalo Calvino. Como ele, são 18 passagens (algumas contendo discurso direto) que se apresentam no final ou no início de cada uma das nove partes do livro, que é composto de 55 histórias descritivas de cidades, com características dos gêneros romance e conto.

A narrativa é um diálogo entre Kublai Khan, conquistador mongol e imperador dos Tártaros, e Marco Pólo, mercador veneziano que relatou suas viagens por esse Império no início do século XIV e que, no livro, é apresentado como o viajante que melhor descreve as cidades ao Grande Khan.

$\mathrm{Na}$ passagem que introduz a segunda parte, há um narrador em terceira pessoa - que se projeta no texto como uma imagem do enunciador (autor-implícito ou autor-modelo). Esse narrador, em vários momentos, dá voz às personagens Marco Pólo e Kublai-Khan, que se manifestam em discurso direto, formando o par interlocutor-interlocutário (que, como tais, se revezam). Em outros momentos, é um narrador onisciente, que descreve os pensamentos das personagens.

As posições enunciativas apresentadas por Bertrand (2003, p. 113) para o discurso narrativo propõem tipos de focalização enunciativa, como a "focalização zero", que se mostra adequada ao discurso analisado. Trata-se do "caso do narrador onisciente que controla o conjunto da cena narrativa, sabe mais que suas personagens e entra em sua interioridade".

\footnotetext{
${ }^{1}$ Primeira versão apresentada como artigo final da disciplina "Seminário de Tópicos Avançados em Análise do Discurso: Discurso e Ideologia”, ministrada pelo Prof. Dr. Antônio Augusto Moreira de Faria, no Mestrado em Estudos Lingüísticos (POSLIN-FALE-UFMG), 2006.
} 


\section{Pressupostos teórico-metodológicos}

A análise aqui apresentada buscou apreender os principais percursos temáticos e figurativos presentes na narrativa de Calvino que foi selecionada para este trabalho. Procurou também desvendar os "planos de leitura" (ou isotopias) propostos. Tais categorias situam-se no componente semântico - nível discursivo do percurso gerativo de sentido. Por essa razão, alguns estudiosos, como Faria (2001), preferem não distinguir os percursos temáticos dos figurativos, chamandoos simplesmente de "percursos semânticos".

O percurso gerativo de sentido, tal como foi proposto pela semiótica greimasiana (ou semiótica do discurso), é um simulacro da produção/recepção dos discursos, sendo constituído de três níveis, que são dotados de uma semântica (os conteúdos investidos nos arranjos sintáticos) e uma sintaxe (os arranjos que organizam os conteúdos). O nível discursivo é o mais superficial e, ao mesmo tempo, o mais complexo dos três. Seu componente semântico, como já foi dito, refere-se ao estudo dos temas, figuras e isotopias. Já no componente sintáxico, analisam-se as projeções da enunciação no enunciado e as relações entre enunciador e enunciatário.

O patamar intermediário - o nível narrativo - é a instância da atualização dos valores, que são, então, assumidos por um sujeito. No âmbito da semântica, estudam-se as modalidades (querer, dever, poder e saber fazer ou ser) e as relações entre sujeitos e entre estes e os objetos, o que desemboca na "semiótica das paixões". Já no âmbito da sintaxe narrativa, tem-se o chamado "enunciado elementar", que consiste na relação entre um sujeito e um objeto, que pode ser tanto uma relação de conjunção (o sujeito tem o objeto) quanto uma relação de disjunção (o sujeito não tem o objeto). Nos textos, em geral, ocorre a passagem de um estado a outro, transformação que caracteriza a narratividade.

Finalmente, no nível fundamental, mais profundo e abstrato, procura-se identificar as oposições do discurso, ou as categorias semânticas - /a/ versus /b/ que estão na base da construção do texto. Fiorin (2005b, p. 27) considera que "a 
categoria semântica do nível fundamental deve dar sentido ao conjunto de elementos do nível superficial". O componente sintáxico, por sua vez, tem um caráter puramente relacional, baseando-se em dois tipos de operação: a asserção e a negação, que fazem passar dos termos contrários /a/ versus /b/ para seus contraditórios / não-a/ e / não-b/, respectivamente.

O componente semântico do nível discursivo, que será aqui tomado como base para nossa análise, é, segundo Fiorin (2005c, p. 19), o campo das determinações inconscientes. Para o autor, "o conjunto de elementos semânticos habitualmente usados nos discursos de uma dada época constitui a maneira de ver o mundo numa dada formação social".

$\mathrm{Na}$ semântica discursiva, as figuras (elementos do mundo natural) e os temas (termos que organizam, classificam, categorizam as figuras) "concretizam" os elementos mais abstratos dos dois níveis anteriores: o fundamental e o narrativo. As figuras criam o "tecido" do texto, seu encadeamento, estabelecendo relações que, identificadas, permitem avaliar a trama que o constitui. No entanto, o figurativo precisa ser assumido por um tema para produzir sentido. Para Bertrand (2003, p. 213), “a tematização consiste em dotar uma seqüência figurativa de significações mais abstratas que têm por função alicerçar os seus elementos e unilos, indicar sua orientação e finalidade, ou inseri-los num campo de valores cognitivos ou passionais".

Já a noção de isotopia pode ser definida como a recorrência de traços que conferem coerência ao discurso. Lara (2004, p. 107) destaca que

para recuperar aquilo que assegura a compatibilidade dos múltiplos percursos temáticos (e/ou figurativos) de um dado discurso, é preciso apreender suas isotopias, pois é a permanência de alguns traços mínimos que vai garantir uma espécie de plano comum que possibilita a homogeneidade desse discurso.

Os percursos semânticos (temáticos e figurativos) e as isotopias representam duas formas distintas de se olhar o mesmo discurso. Segundo Barros (1988, p. 125), os percursos temático-figurativos estão na dimensão paradigmática (umas figuras chamam às outras; um tema sucede ao outro). As isotopias, por sua vez, estão no 
nível sintagmático e se referem aos planos de leitura, em que a recorrência dos traços abstratos e figurativos correspondem à sintagmatização das configurações. Bertrand (2003, p.190) considera que a coerência de um texto assenta, de início, em uma suposição de isotopia, antecipada pelo leitor e atualizada pelos elementos que forem compatíveis com o plano de leitura imaginado.

\section{Os temas, figuras e isotopias da narrativa}

Em primeiro lugar, apresentemos o diálogo escolhido para análise:

- Os outros embaixadores me advertem a respeito de carestias, concussões, conjuras; ou então me assinalam minas de turquesa novamente descobertas, preços vantajosos nas peles de marta, propostas de fornecimento de lâminas adamascadas. E você? - o Grande Khan perguntou a Pólo. - Retornou de países igualmente distantes e tudo o que tem a dizer são os pensamentos que ocorrem a quem toma a brisa noturna na porta de casa. Para que serve, então, viajar tanto?

- É noite, estamos sentados nas escadarias do seu palácio, inspire um pouco de vento - respondeu Marco Pólo. - Qualquer país que as minhas palavras evoquem será visto de um observatório como o seu, ainda que no lugar do palácio real exista uma aldeia de palafitas e a brisa traga um odor de estuário lamacento.

- O meu olhar é de quem está absorto e medita, admito. Mas e o seu? Você atravessa arquipélagos, tundras, cadeias de montanhas. Seria melhor nem sair daqui.

$\mathrm{O}$ veneziano sabia que, quando Kublai discutia, era para seguir melhor o fio de sua argumentação; e que as suas respostas e objeções encontravam lugar num discurso que ocorria por conta própria na cabeça do Grande Khan. Ou seja, entre eles não havia diferença se questões e soluções eram enunciadas em alta voz ou se cada um dos dois continuava a meditar em silêncio. De fato, estavam mudos, os olhos entreabertos, acomodados em almofadas, balançando nas redes, fumado longos cachimbos de âmbar.

Marco Pólo imaginava responder (ou Kublai imaginava a sua resposta) que, quanto mais se perdia em bairros desconhecidos de cidades distantes, melhor compreendia as outras cidades que havia atravessado para chegar até lá, e reconstituía as etapas de suas viagens e aprendia a conhecer o porto de onde havia zarpado, e os 
lugares familiares de sua juventude, e os arredores de casa, e uma pracinha de Veneza em que corria quando era criança.

Neste ponto, Kublai Khan o interrompia ou imaginava interrompêlo ou Marco Pólo imaginava ser interrompido com uma pergunta como:

- Você avança com a cabeça voltada para trás? - ou então: - O que você vê está sempre às suas costas? - ou melhor: - a sua viagem só se dá no passado?

Tudo isso para que Marco Pólo pudesse explicar ou imaginar explicar ou ser imaginado explicando ou finalmente conseguir explicar a si mesmo que aquilo que ele procurava estava diante de si, e, mesmo que se tratasse do passado, era um passado que mudava à medida que ele prosseguia a sua viagem, porque o passado do viajante muda de acordo com itinerário realizado, não o passado recente ao qual cada dia que passa acrescenta um dia, mas um passado mais remoto. Ao chegar a uma nova cidade, o viajante reencontra um passado que não lembrava existir: a surpresa daquilo que você deixou de ser ou deixou de possuir revela-se nos lugares estranhos, não nos conhecidos.

Marco entra numa cidade; vê alguém numa praça que vive uma vida ou um instante que poderiam seu seus; ele podia estar no lugar daquele homem se tivesse parado no tempo tanto tempo atrás, ou então se tanto tempo atrás numa encruzilhada tivesse tomado uma estrada em vez de outra e depois de uma longa viagem se encontrasse no lugar daquele homem e naquela praça. Agora, desse passado real ou hipotético, ele está excluído; não pode parar; deve prosseguir até uma outra cidade em que outro passado aguarda por ele, ou algo que talvez fosse um possível futuro e que agora é o presente de outra pessoa. Os futuros não realizados são apenas ramos do passado: ramos secos.

- Você viaja para reviver o seu passado? Era, a esta altura, a pergunta do Khan, que também podia ser formulada da seguinte maneira: - Você viaja para reencontrar o seu futuro?

E a resposta de Marco:

- Os outros lugares são espelhos em negativo. O viajante reconhece o pouco que é seu, descobrindo o muito que não teve e o que não terá.

Conforme já foi dito, na Introdução, o texto acima inicia a segunda parte do livro As Cidades Invisiveis e retrata um diálogo entre Kublai Khan e Marco Pólo. Lembramos aqui que os percursos temático-figurativos (ou percursos semânticos) e 
as isotopias representam duas formas distintas - porém, complementares - de se olhar o mesmo discurso. Dito isso, passamos à análise da narrativa, por meio da apreensão dos elementos citados.

Há, inicialmente, a oposição objetividade vs subjetividade. O tema da objetividade (dos relatos) está relacionado ao ator coletivo outros embaixadores, que traz notícias boas e más sobre o império (sobre abundância e escassez, objetivamente). As riquezas do império estão representadas pelas figuras minas de turquesa, peles de marta, lâminas adamascadas; os problemas, por carestias, concussões, conjuras. Os lexemas advertem e assinalam, que se referem ao ator coletivo, acentuam o efeito de sentido de objetividade no relato desses viajantes.

É possível constatar que Kublai-Khan é interlocutário de outras personagens, além de co-interlocutor de Marco Pólo, ator esse que figurativiza o tema da subjetividade (dos relatos), subentendido em "pensamentos que ocorrem a quem toma a brisa noturna na porta de casa", opondo-se, portanto, ao tema da objetividade relacionado ao ator coletivo.

As figuras, já mencionadas acima (minas de turquesa, peles de marta, lâminas adamascadas), que se referem ao império de Kublai Khan, demonstram a riqueza e o luxo das condições de vida do imperador. Por sua vez, as figuras: países distantes, viajante, itinerário, bairros desconhecidos, cidades distantes, encruzilhada, estrada, referem-se às condições de vida de Marco Pólo. Essas figuras, encadeadas, revestem os temas que compõem o percurso das viagens.

São apresentadas duas classes sociais, associadas aos temas da riqueza (sintetizada na figura do palácio real) e da pobreza (concretizada nas figuras: aldeia de palafitas, estuário lamacento), utilizadas, opositivamente, para enfatizar que a construção de sentido depende dos pontos de vista.

Identificamos, a partir desse parágrafo, o tema da visão de mundo ou do pensamento, esse último conceituado por Fiorin (2005c, p.33) como "a faculdade de se orientar no mundo ou o reflexo subjetivo da realidade objetiva". Os discursos expressam, assim, uma consciência formada pela diversidade de regras sobre 
comportamentos sociais e experiências diversas que acompanham o sujeito ao longo de sua existência, em determinados contextos, que ele reflete e refrata, delineando um ponto de vista. Nessa perspectiva, a figura observatório como o sen refere-se ao lugar do interlocutário (nesse caso, Kublai Khan) e reforça a relação do "ponto de observação" com a diversidade das construções de sentido, revelando a heterogeneidade que perpassa o sujeito (e seu discurso).

Entre outros aspectos relevantes, aí se estabelece, implicitamente e de forma metonímica, o ator coletivo que mobiliza os diversos sujeitos inseridos nas (ou entre as) duas classes sociais descritas, cada "observatório" ou ponto de vista com suas possibilidades de sentido e identidade ideológica, numa referência também implícita às construções de sentido do próprio leitor.

Figuras como absorto, medita, pensamentos, evoquem, observatório, cabeşa, silêncio, imaginava, passado contribuem para estabelecer o tema da visão de mundo, remetendo à construção da interlocução, na qual se apresenta, sutilmente ou não, a "expressão" de um posicionamento ideológico. Para Bakhtin (1986, p.97), "a teoria da expressão supõe inevitavelmente um certo dualismo entre o que é interior e o que é exterior, com primazia explícita do conteúdo interior, já que todo ato de objetivação (expressão) procede do interior para o exterior" - sem esquecer que, para o autor, a estrutura da atividade mental é social, assim como a da sua objetivação exterior (BAKHTIN, 1986, p.100).

As figuras arquipélagos, tundras, cadeias de montanhas apontam os possíveis espaços do interlocutário (nesse caso, Marco Pólo) e permitem identificar a mobilidade mental dos sujeitos-interpretantes (metonimicamente representados por Kublai Khan), enfatizando o mesmo tema. "Seria melhor nem sair mais daqui" cria um efeito de sentido de vantagem para Kublai Khan: há o implícito de que ele faz "viagens" sem sair do lugar.

O percurso temático da visão de mundo é construído através do tempo e do espaço, concretizando-se nas figuras que representam o "hoje" (viagens) e o "ontem" (familia, infância, juventude, casa, pracinha, Veneza), que deixam implícita uma 
certa indistinção da fronteira entre o presente e o passado de Marco Pólo, desencadeados ambos através dos espaços. A última frase do discurso associa o reconhecimento da disjunção "deixou de ser ou de possuir" ao espaço no qual o viajante se encontra, subentendendo que viajar contribui para a conjunção com o autoconhecimento ("surpresa daquilo que você deixou de ser").

O enunciado "aquilo que ele procurava estava diante de si" evoca o presente, o agora, que se completa nas experiências passadas, por meio do pensamento. $\mathrm{O}$ lexema finalmente ("finalmente conseguir explicar a si mesmo") cria o efeito de sentido do reconhecimento, do "cair em si". Apreende-se do discurso que a visão de mundo estabelecida na inter-relação do sujeito no tempo e no espaço contribui para o conhecimento de si mesmo. Identifica-se, assim, o tema do autoconhecimento, que se imbrica com o tema da visão de mundo.

O conceito de Weltanschaunng sobre "visão de mundo" é a tradução literal da expressão que designa a forma como o mundo é apreendido pelo homem. Homem que busca essa apreensão pelo seu conjunto de princípios, pontos de vista e convicções, determinantes de sua atitude frente a si mesmo e/ou à realidade que o cerca ou ainda que ele apreende (KRAPIVINE,1986). O conceito de subjetividade, muito amplo, pode ser lido, num mesmo sentido, como a "capacidade do locutor de se posicionar como sujeito”, como descreve Benveniste (1966, p. 259-260). A esse sujeito "individualizado" de Benveniste opõe-se, no entanto, o sujeito "coletivizado": aquele que "fala" de um lugar social, afetado por coerções diversas, como o definem, por exemplo, Bakhtin e Maingueneau. Trata-se, pois, de um sujeito em tensão constante entre o pólo individual e o pólo social, o que leva Orlandi (1987, p.189) a afirmar que "não existe nem um sujeito absolutamente dono de si, nem um sujeito totalmente determinado pelo que lhe vem de fora".

A partir do quarto parágrafo, podemos identificar, no discurso, o percurso temático da complexidade da comunicação bumana, que começa a se delinear no segundo parágrafo, quando Pólo sugere que Kublai “inspire” o vento e não "aspire” ou "respire", implicitando que o Imperador deve buscar inspirar-se para compreender 
o que ele vai dizer. A figura do vento remete ao ar, componente do quarteto: ar, água, terra, fogo, elemento descrito pela astrologia como agente de um estado de agregação vaporosa, uma radiação que proporciona movimento livre e desimpedido. No discurso, pode ser comparado ao movimento virtual realizado por Kublai Khan no processo de interpretação.

A complexidade da troca comunicacional é tematizada na forma sutil de interação entre as duas personagens - "entre eles não havia diferença se questões e soluções eram enunciadas em alta voz ou se cada um dos dois continuava a meditar em silêncio" -, podendo-se identificar um discurso não legitimado pela ideologia dominante. A orientação de "objetividade", ponto de vista da sociedade hegemônica, não reconhece formas mentais de interação comunicacional, por sua vez valorizadas no discurso analisado. "Num discurso que ocorria por conta própria na cabeça do Grande Khan", subentende-se que o compartilhamento acontece num plano que transcende a comunicação oral entre eles, reforçando o percurso temático da complexidade da comunicação, comunicação essa que pode se estabelecer por meio de diferentes modos de discurso.

As figuras almofadas, redes, cachimbos de âmbar trazem, de forma subjacente, o tema do conforto, o que remete à satisfação com a troca comunicacional pouco ortodoxa, que é efetivada, mesmo fora dos padrões estabelecidos na sociedade dominante. Identificamos, mais uma vez, um discurso (contra)ideológico que se opõe, portanto, aos padrões desejáveis de objetividade. Considerando que o intradiscurso tem o percurso temático-figurativo (ou "percurso semântico") como principal categoria descritiva, Faria (2001, p. 31) explica como identificar sua relação com o interdiscurso:

(...) o discurso abrange duas dimensões, integradas e complementares: por um lado, a do intradiscurso, organiza-se em um conjunto, uma trajetória de sentidos que se desenvolve ao longo do texto; por outro lado, a do interdiscurso, constitui-se por contradição, por oposição a outros discursos.

Pelo que se pode extrair do discurso, a visão de mundo é, pelo menos em parte, construída pelas escolhas efetuadas ao longo do tempo, que determinam as 
possibilidades de existência - "ele podia estar no lugar daquele homem (...) se tanto tempo atrás numa encruzilhada tivesse tomado uma estrada em vez de outra". A figura ramos secos refere-se ao vazio da não-experiência, representada no futuro que não se realiza, valorizando as viagens (mobilidade), que são associadas à experiência de vida e ao autoconhecimento.

As perguntas de Kublai, no final da narrativa, sugerem que talvez as viagens de Pólo tenham o objetivo de acessar um futuro não realizado, além de proporcionarem uma releitura do passado. A resposta do veneziano novamente relaciona o espaço presente ("espelho em negativo") ao reconhecimento da disjunção, tanto do passado ("o muito que não teve") quanto do futuro ("o que nunca terá”).

O discurso apresenta planos de leitura específicos ou isotopias. A coerência semântica, fruto da permanência de um efeito de sentido ao longo do discurso, começa na formulação de hipóteses pelo leitor, "horizontes de expectativas," que serão ou não confirmados. A isotopia espacial é o primeiro plano de leitura identificado e pode ser reconhecida nos diálogos (orais ou virtuais) entre Kublai Khan e Marco Pólo, que se referem tanto aos deslocamentos do viajante quanto à descrição que ele faz das cidades percorridas. Os relatos sobre os espaços podem ser objetivos (com o dos "demais embaixadores") ou subjetivos (como os de Pólo).

Ao longo da narrativa, as viagens são valorizadas enquanto desencadeadoras de pensamentos que constroem uma visão de mundo (que se materializa na e pela linguagem), no âmbito de uma isotopia que poderíamos chamar de "representacional" (na medida em que os diferentes pontos de vista assumidos "representam" diferentemente a realidade). Esse "plano de leitura" remete aos temas da subjetividade e do autoconhecimento e, por extensão, à interioridade, à construção de sentido efetuada por cada um.

A isotopia interacional discursiva (ligada ao percurso temático-figurativo da complexidade da comunicação) articula-se à isotopia representacional e comanda a significação global do discurso. A complexidade da troca comunicacional é 
evidenciada pelos temas citados e figurativizada nos atores Marco Pólo e Kublai Khan que, confortavelmente, instalados em almofadas e fumando cachimbos de âmbar, relacionam-se por meio de discurso bastante original.

\section{Conclusão}

O discurso analisado trata da complexidade da comunicação, em que a expressão e a compreensão se estabelecem como movimentos singulares diretamente ligados às experiências e condições de vida dos sujeitos inseridos na relação tempo-espaço. Conduzido pelo percurso temático das viagens que conta com figuração abundante, o discurso pontua a diferença entre a objetividade e a subjetividade dos relatos, tematiza a visão de mundo dos sujeitos, o autoconhecimento e destaca um outro modo de discurso, mais sutil que a comunicação oral.

Identificou-se, a partir daí, uma ideologia que se opõe à "objetividade dos discursos" defendida pela sociedade hegemônica, tendo como isotopias ou planos de leitura, o espaço (das viagens), a representação (de acordo com as visões de mundo) e a interação comunicacional (por meio de uma expressão complexa e pouco convencional).

\section{Referências Bibliográficas}

BAKHTIN, Mikhail; VOLOCHÍNOV, V.N. Marxismo e filosofia da linguagem. Ed. São Paulo:Hucitec, 1986.

BARROS, Diana L.P. Teorias do discurso: Fundamentos semióticos. São Paulo: Atual Editora, 1988.

BENVENISTE, Émile. Problèmes de linguistique générale I. Pari :Gallimard, 1966.

BERTRAND, Denis. Caminhos da semiótica literária. São Paulo: Edusc, 2003.

CALVINO, Ítalo. As cidades invisiveis. São Paulo: Ed. Schwarcz, 1994, p. 27-29.

FARIA, Antônio Augusto M. Interdiscurso e intradiscurso: da teoria à metodologia. In: MENDES, Eliana; OLIVEIRA, Paulo; BENN-IBLER, 
Veronika (Org.). O novo milênio: Interfaces linguísticas e literárias. Belo Horizonte: Ed. UFMG, 2001.

FIORIN, José Luiz. As astúcias da enunciação: As categorias de pessoa, espaço e tempo. São Paulo: Ed. Ática, 2005a.

. Elementos de análise do discurso. São Paulo: Ed. Contexto, 2005b. . Linguagem e Ideologia. São Paulo: Ed. Ática, 2005c.

KRAPIVINE, V. O que é o materialismo dialético. (ABC dos Conhecimentos Sociais). Mscou: Ed. Progresso, 86.

LARA, Glaucia M.P. O que dizem da lingua os que ensinam a lingua. Campo Grande: Ed. UFMS, 2004.

ORLANDI, Eni. A linguagem e seu funcionamento. Campinas: Ed.Pontes, 1987. 